\title{
DE SAN FERNANDO A CAYETANO HEREDIA: HOMENAJE AL ALMA MATER DE LA MEDICINA PERUANA*
}

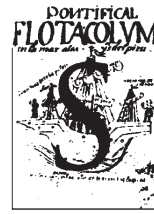

i es cierto que el Protomedicato existió en el Perú desde 1570 hasta 1848 y que las Constituciones de la Universidad de San Marcos, desde la primera de 1571, consignaban cursos de medicina y grados de doctor en esta materia, ${ }^{1}$ no lo es menos que la enseñanza médica adquiere carácter orgánico al crearse en 1811 el Real Colegio de Medicina y Cirugía de San Fernando. Ubicado en el área donde hasta hace cuatro décadas funcionó el Ministerio de Gobierno y Policía, en la Plaza Italia de Lima, este Colegio creado y dirigido por Hipólito Unanue, pasa a denominarse en 1821, por decisión del General San Martín, Colegio de la Independencia, como homenaje a la contribución de sus maestros y alumnos a la causa de la emancipación. Producida la reforma de los estudios médicos se convierte en la Facultad de Medicina de San Fernando, fundada el 6 de octubre de 1856 por Cayetano Heredia. Cambia de local en 1903 cuando se inaugura el actual edificio de la Av. Grau. ${ }^{2}$

Desde su génesis el Real Colegio, el Colegio de la Independencia o la Facultad de Medicina de San Fernando, ha vivido y expresado los vaivenes del acontecer nacional. Es parte de su historia. Por ello sería equivocado intentar algún juicio sobre el significado pasado o presente de San Fernando, si no se tiene en cuenta el entorno social, económico y político en el que se ha desenvuelto.

Por más de un siglo San Fernando ha tenido la exclusividad en la formación de los profesionales de la medicina en el Perú. Recién en 1958 se inicia el funcionamiento de las Facultades de Medicina en Universidad Nacional de Trujillo en La Libertad y en la Universidad de San Agustín de Arequipa. ${ }^{3}$ Por lo tanto, hasta la mitad de la centuria que termina ha sido la única estirpe de la medicina peruana. Hoy contamos con doce facultades de Medicina. Ha sido precisamente en ese medio siglo cuando se fueron plasmando en el

* ACTA HEREDIANA, Vol. 11, Abril - Septiembre, 1991, págs. 34-45.
Perú profundos cambios que han gravitado sobre sus instituciones y sectores dando lugar a la compleja situación que ahora afrontamos. Ha sido ésta la etapa en la que una crisis singular, todavía no totalmente analizada, conmovió a nuestra vieja y querida Alma Mater. Lo ocurrido en el campo académico y sus consecuencias en la Medicina y Salud Pública Nacional, lo pasado, el presente y lo porvenir, bueno o malo, anotado en el debe o en el haber de la historia es parte consustancial y/o herencia de esa cuna de nuestra medicina.

No puede sorprender, por la naturaleza de la disciplina, que llegado al Perú el positivismo éste anclara con firmeza en la escuela médica. Si en otras facultades se entronizó con entusiasmo y luego entró en debate o alternancia con el espiritualismo, que en algún momento se dejó sentir en San Marcos, no se encuentra evidencia de esta ocurrencia en la Facultad de Medicina. Por el contrario, cada vez se puso más énfasis en la objetividad y experimentación. Sólo muy tardíamente, en esa media centuria, con la introducción de la medicina psicosomática, insurge una tendencia holística* que da nueva dimensión al positivismo original. Si el anarquismo y, sobre todo, el marxismo lograron eco en San Marcos, su influjo no fue significativo en San Fernando. Sin embargo, el marxismo tocó por lo menos a sectores reducidos del profesorado y sembró adeptos de creciente entusiasmo en el estudiantado fernandino. Este germen habría de tener repercusión en las ocurrencias y sucesos que habremos de comentar más adelante.

\section{SAN FERNANDO Y EL MOVIMIENTO REFORMISTA}

En 1919 1 a juventud estudiosa peruana fue impactada por la presencia y verbo del maestro y político Alfredo Palacios, quien trajo al Perú el mensaje del movimiento reformista de Córdoba dirigido a los "hombres libres de Sud América". Recogido primero

\footnotetext{
* De holism (inglés) la visión que un todo integrado tiene una realidad independiente de y más grande que la suma de sus partes.
} 
en la Facultad de Letras, caló pronto en otras facultades, originando la Reforma Universitaria de 1919. Este movimiento expresa, de un lado, un genuino ideal de superación académica y, de otro, las simientes de una temprana reacción social. Basadre ${ }^{4}$ nos dice que "las demandas estudiantiles se fundamentaron en el anhelo de mejoramiento y modernización de la enseñanza", "una protesta contra lo que entonces se calificó como esclerosis de la docencia". Por primera vez, los estudiantes se dirigen al país en nombre de un ideal de cultura. Sánchez, ${ }^{5}$ otro protagonista estudiantil de la época, enfatiza la necesidad de "liquidar el estado feudal de la universidad". De algo así como cien cátedras veinticinco estaban en manos de catorce personas de un mismo grupo, la mayoría del clan civilista. Los objetivos de dar participación a los estudiantes en ciertas decisiones universitarias, docencia libre, derecho de tacha, supresión de listas y premios, jubilación de catedráticos ancianos, oportunidad para que los estudiantes trabajen, becas para los estudiantes pobres, etc. indican bien una voluntad de mejora docente y una definida inquietud social y política.

La evolución del movimiento reformista fue descabalada y anecdótica. Los alumnos pronto se fraccionaron,* primero fugazmente, entre el Comité Central de Reforma y la Federación de Estudiantes, y luego, con los profesores, entre los que aceptaban las decisiones del Gobierno y los que se oponían a éste. Desde la más temprana etapa del conflicto estudiantil San Fernando fue la voz de la derechura académica. Un decreto expedido por el Gobierno el 20 de septiembre de 1919 y luego la Ley 4002 concedieron algunas de las demandas estudiantiles: cátedras libres, representación estudiantil (los alumnos elegían a los profesores que habrían de representarlos en el Consejo Universitario), suspensión de listas y vacancia de cátedras con enseñanza deficiente (tácito reconocimiento al derecho de tacha), pero los nuevos

* La pugna motivó hasta un duelo entre Hernando de Lavalle, Presidente de la Federación de Estudiantes y José Manuel Calle, Presidente del Comité de Reforma. nombramientos se harían por resolución ministerial. San Fernando salió entonces a la palestra protestando, lo que originó la Ley 4004 que devolvió el fuero organizativo a la Universidad. Cuando en 1921, San Marcos es recesado por voluntad de numerosos catedráticos como consecuencia del asalto de las turbas gobiernistas al claustro, en un afán de frenar las críticas de Víctor Andrés Belaúnde en el conflicto entre el Gobierno y el Poder Judicial, una vez más alumnos y profesores se banderizan. El Comité Revolucionario de Reforma Educativa, alineado con el Gobierno, negó el derecho al receso y habló de una "Universidad renovada". Otros alumnos y profesores estaban en la trinchera opuesta. ${ }^{* *}$ El Gobierno, ni corto ni perezoso, por decreto declaró la vacancia del Rectorado y de las cátedras cuyos profesores habían sido tachados o se habían manifestado a favor del receso. En dramático pronunciamiento publicado en la primera página de "El Comercio" el 25 de mayo de 1921, los maestros de la Facultad de Medicina se dirigen a la nación manifestando su decisión de mantener el receso en "servicio de la autonomía universitaria, hermosa conquista cultural y preciado tesoro de las naciones civilizadas". Recordaron que este receso "no es el primero...". "Los maestros de la Facultad de Medicina se vieron obligados a abandonar la docencia en gravísima oportunidad anterior a la presente cuando las hordas chilenas se adueño (sic) de la Escuela de San Fernando". "En exclusivo servicio de la nacionalidad, en defensa de un patrimonio moral inalienable, adoptamos esta actitud declarando que se encuentra absolutamente exenta de toda finalidad política". Podríamos decir que esta declaración encierra una filosofía que habría de ser viga maestra del espíritu sanfernandino.

Con la rebeldía de un grueso número de profesores el caos se apodera de San Marcos. Un nuevo decreto

** Guillermo Hoyos Osores, Leonidas Ponce Sobrevilla, Edgardo Rebagliati, Javier Arias Schreiber, figuraban, entre muchos de los estudiantes en favor del receso. Víctor Raúl Haya de la Torre, Luis Alberto Sánchez y Raúl Porras, entre otros, se negaron a solidarizarse con el receso, aunque rechazaron la intervención del gobierno. 
expedido e131 de mayo 1921 declara en reorganización a la Universidad de San Marcos.

El primer centenario de la independencia nacional encuentra a la Universidad en "receso". La falta de aprobación por el Senado del proyecto de "Constitución Universitaria" presentado por Julio C. Tello y J..A. Encinas, que contenía las ideas renovadoras del primero, extraídas de su experiencia en USA, frustró un auroral intento de modernización. Finalmente un decreto expedido por Leguía en abril de 1922, dando transitoriamente a la Universidad la condición de institución particular, acabó con la intervención del Gobierno y permitió la reapertura de la Universidad en la situación pre-reformista. Todo quedó en nada. El Gobierno tranquilizó las aguas y los catedráticos consiguieron la detención de una reforma que no era de su agrado. Entró así la Universidad a lo que habría de ser una constante de su evolución. Esperar una nueva ley que pusiera las cosas en orden. Mientras tanto gritas, protestas, llamados de asambleas y huelgas cada vez que la situación política se agitaba.

\section{LA GENERACIÓN DE LA MEDIA CENTURIA}

Al amparo de las "conquistas" alcanzadas y perdidas se relajó la disciplina, las exigencias y el rigor académico. San Fernando, una vez más, resistió esa declinación.

En 1928 una autorización legislativa puso en vigencia un nuevo Estatuto Universitario que entregaba la autoridad a un Consejo Nacional de Enseñanza Universitaria constituido por el Ministro de Educación. Se nombró al veterano y respetado maestro Alejandro Deustúa como Rector y a otros distinguidos personajes en los decanatos. La Universidad permaneció temporalmente en calma pero sin mejoras sustanciales en las facilidades para el estudio y la investigación. San Fernando, sin embargo, ya había conseguido por el prestigio y reconocimiento de sus catedráticos la dación de la Ley 5604 que ordenaba la construcción de un Policlínico para la Facultad, financiado con un impuesto de $6 \%$ ad valorem a los productos farmacéuticos de manufactura extranjera. Producido el derrocamiento de Leguía se expide un decreto que establece la representación estudiantil directa en los Consejos de la Universidad y otro denominado "Constitución de la Universidad de San Marcos". Ambos son de efímera duración, pues desaparecen con la llegada de Sánchez Cerro a Palacio en 1932. La Universidad es clausurada de 1932 a 1935 y las reivindicaciones estudiantiles no figuran en el Estatuto promulgado por Benavides en 1935, ni en la Ley de Educación de 1941.

Juzgando el período de 1919-1930, Basadre afirma con acierto: "Puede decirse que desde entonces y con ritmo creciente, salvo en la Facultad de Medicina, no se graduó sino el que no quiso". En esta la isla universitaria que encontramos, en la década del cuarenta, los estudiantes de medicina que pertenecemos a lo que puede llamarse la generación de la media centuria.* El marxismo y su colateral el aprismo, fueron haciendo carne en sectores cada vez más numerosos del estudiantado. La politización fue in crecendo. San Fernando fue menos dúctil pero no impenetrable. En otras Facultades ya se hizo común el estudiante político de oficio, que se matriculaba año a año sin importarle los exámenes. Malo o pésimo en los estudios pero imparable en los discursos en las asambleas. No recuerdo en la Facultad de Medicina de mi tiempo alguien que mereciera ese calificativo. Si hubo quienes siendo opacos estudiantes se convertían en fogosos adalides en las polémicas y asambleas universitarias.

Los de la generación de la media centuria participamos como alumnos en los procesos estudiantiles que desembocaron en la reconquista del eje del planteamiento reformista: la representación estudiantil directa. Para entonces la pugna en la Universidad se daba entre los sectores politizados y los llamados "independientes". Los primeros eran apristas o comunistas. Su fuerza variaba de Facultad en Facultad. En San Fernando los apristas esta-

\footnotetext{
* Arbitrariamente puede así designarse a quienes fueron estudiantes y llegaron a profesionales entre 1940 y 1960.
} 
ban mejor organizados y eran muy activos. Importantes líderes comunistas como Asunción Caballero Méndez venían de la cantera sanfernandina y esto les daba alguna presencia pero, hasta donde llega mi memoria, los apristas eran más numerosos. Los “independientes” constituían el núcleo largamente mayoritario pero su falta de cohesión e interés en los asuntos del manejo de la Universidad no les permitía sino, ocasionalmente, alcanzar alguna representación estudiantil. Estaban más interesados en los estudios y en hacer prácticas en laboratorios y servicios clínicos, a la caza de un comienzo de especialización. Un grupo de alumnos, tres promociones anterior a la mía, publicaban La Gaceta Médica, * revista estudiantil que alcanzó buen nivel y larga duración. En mi promoción fuimos capaces de sacar a luz La Hoja Médica, ** de menor permanencia. Se trataba de esfuerzos netamente académicos que acusaban un acendrado idealismo, ingenuidad, voluntad de superación y solidaridad. El Centro de Estudiantes de Medicina tenía también su publicación, de irregular aparición y otros contenidos. La oleada democrática de 1945 reavivó los entusiasmos juveniles. José Luis Bustamante y Rivero hablaba de juridicidad y democracia con una propiedad que impactaba en las inteligencias. El Apra coadyuvó a su entronización en la Presidencia y devino fortalecido del proceso y por ende en la Universidad. Como los comunistas coincidían en el asunto del tercio estudiantil el tema cobró empuje. San Fernando contaba también con profesores politizados que defendían la tesis. La Ley 10555 de abril de 1946, sanciona la representación estudiantil de un tercio en todos los organismos de gobierno de la Universidad. Luis Alberto Sánchez, maestro y líder aprista, es elegido Rector de San Marcos y el Dr. Sergio Bernales, catedrático de medicina y miembro también del partido aprista, Decano de San Fernando. ${ }^{6}$ Hubo mucha pugna y jaleo para estas elecciones y salió

* Ricardo Subiría. Guido Battilana, Jaime Scerpella, Jaime Romero y Luis Ginocchio, constituían el Comité de Redacción.

** Julio Arriola Raya, Eugenio Beltroy Patrón, Hiram Benavente Benavides, Renzo Como Montini, Carlos Roe Gómez, Neptalí Pastor y Javier Arias-Stella, fueron los Redactores Fundadores. ya a relucir la violencia y el sectarismo pero, elecciones al fin, no cabía sino respetarlas. Si en las breves "conquistas estudiantiles" derivadas del movimiento reformista de 1919 hubo mucho idealismo y sólo un incipiente ingrediente político, en la reconquista del tercio en 1946 los intereses políticos fueron los predominantes. ${ }^{* * *}$ Ya la Universidad se había convertido, seguramente de buena fe, en un objetivo para aquellos que pretendían hacer "la gran transformación o revolución social del Perú”. Pero la historia.de la universidad peruana volvió a repetirse. En dos años el golpe del General Odría, restituyó el estado de cosas de la Universidad a la situación pre-reformista. La vigencia del cogobierno del tercio en la Facultad de Medicina en aquel período no fue positiva. Desorganización, disminución del nivel educativo, ingreso de alumnos por encima de la capacidad docente, designación de los delegados estudiantiles según criterios políticos y "desenfrenada dictadura, estudiantil que arrolló y subyugó a la opinión mayoritaria de los profesores". "Esta negativa experiencia influyó notablemente para modelar la solidez de la posición del profesorado sanfernandino en la crisis de 1960.

\section{UNA BREVE ETAPA DE ORO}

Pero al margen del proceso reformista otros cambios se habían también operado en la Facultad de Medicina que, por su significación, no pueden ser ignorados.

Si el primer intento de poner a tono a la Facultad con las nuevas corrientes que venían de Norteamérica no fue exitoso, una acción más directa y pragmática si lo logró. Julio C. Tello en su fallido proyecto de ley y en su libro Reforma Universitaria, ${ }^{8}$ intenta y propone una nueva Universidad con Escuela Especial de Investigación (Escuela de Altos Estudios), y con una organización celular con Secciones, Departamentos e Institutos. Una Universidad con Laboratorios que permita no sólo conservar los conocimientos y enseñar sino también investigar. Julio C. Tello, ese extraordinario peruano de tantos y tan in-

\footnotetext{
*** Luis Alberto Sánchez era Rector y Diputado de la Nación.
} 
conmensurables logros, no pudo ver colmado su ideal de cambio. Le correspondería también a otro gran hombre, por distintos caminos, inyectar una nueva y vivificante savia a la Facultad de Medicina. La presencia del Dr. Alberto Hurtado Abadía, marca una etapa singular en la evolución de nuestra Alma Mater. ${ }^{9}$ Graduado y especializado en Norteamérica introduce en el Perú el método estadístico en la investigación médica. Ésta había sido hasta entonces básicamente casuística especulativa y de apreciaciones cualitativas. Hurtado incorpora al análisis cuantitativo y el rigor científico. El genio de Carlos Monge Medrano, había abierto a los peruanos el laboratorio natural de las alturas andinas. Hurtado holló por este camino con metodología de avanzada y al hacerlo introdujo en nuestro medio los más sofisticados y actualizados desarrollos tecnológicos. La medicina peruana pasa así de la etapa europea, fundamentalmente francesa, que había sido su molde tradicional a la modernidad que ya entonces comenzaba a significar la escuela americana. Surgen las nuevas especialidades. Germina el entusiasmo en la juventud estudiosa médica. Las revistas más acreditadas del mundo, dan cuenta de los resultados de las investigaciones de la pléyade de médicos peruanos, que bajo la égida de Alberto Hurtado se multiplican día a día y trabajan en todas las ramas de la fisiología y patología médica. Paralelamente Honorio Delgado, Oscar Trelles, Pedro Weiss, Telémaco Battistini, Carlos GutiérrezNoriega y Hugo Pesce, habían iniciado nuevas áreas de investigación y congregado fructíferos seguidores. En otros ámbitos Ovidio García-Rossel, Oscar Soto y Víctor Alzamora Castro cumplían también con brillo y eficiencia y en el campo quirúrgico la destacada y pionera labor de Guillermo Gastañeta y Carlos Villarán había constituido ya sendas y activas escuelas en los Hospitales Dos de Mayo y Arzobispo Loayza. Llegó así una etapa en la que la medicina peruana batalló de igual a igual con los protagonistas del avance en las fronteras del conocimiento médico.* Mucho de lo alcanzado precisamente en ese

* Es obvio que el juicio expresado comprende la producción científica de los primeros años de la Universidad Peruana Cayetano Heredia, que fueron la "vis a tergo" de esa etapa de San Fernando. período es lo que da asidero para afirmar, como lo hace Guerra-García, ${ }_{10}$ que el mayor aporte de investigación original en la universidad peruana proviene de médicos. David Sobrevilla ${ }^{11}$ cuestiona esta posición y considera que la filosofía o la historia ocupan un lugar preeminente. Sostiene su alegato aduciendo que la filosofía peruana es "según opinión fundamentada de expertos extranjeros competentes (I. Romero, I. Hollhuber) una de las tres tradiciones filosóficas de más importancia en América Latina" y que "la interpretación dada por Basadre del desarrollo republicano del Perú es, sin lugar a dudas, por el manejo bibliográfico, la metodología empleada y la amplitud de perspectivas, uno de los mejores trabajos históricos del continente".

Sobrevilla parece no tener en cuenta que GuerraGarcía se refiere a que en medicina hay aportes que no son sólo meritorios en el ámbito latinoamericano o continental, sino que forman parte del contingente original o de frontera del conocimiento médico mundial y que son reconocidos con ese carácter.**

Los tiempos soplaban favorables y el Decanato del Dr. Oswaldo Hercelles García, hombre de singular dinamismo y calidad humana, imprimió un especial énfasis al desarrollo de la infraestructura y equipamiento de la Facultad, favoreciendo a la atmósfera de superación y estímulo. No puede extrañar que en pocos lustros Hurtado se convirtiera en un líder dentro de San Fernando y que llegara al Decanato. Su obra aquí también fue relevante. Vigentes en su mente los esquemas organizativos norteamericanos introduce, por primera vez en el Perú, el profesorado a tiempo completo y dedicación exclusiva y auténticos residentados médicos (con profesores y residentes dedicados a horario completo a las tareas de enseñar y entrenarse en específicas especialidades). Esto y la proliferación

\footnotetext{
** De otro lado, en todo juicio valorativo hay que tener en cuenta que en contraste con la filosofía, literatura, pintura, música y otras manifestaciones del espíritu, la ciencia produce resultados concretos. Por eso al margen de su inmenso valor cultural es el gran motor del avance de la civilización. ${ }^{12}$
} 
de becas de entrenamiento en el exterior y el logro de importantes donaciones para la investigación, producto las más de las veces de sus conexiones y prestigio, aunado al nivel de los profesores arriba mencionados y de sus respectivos discípulos, hacen vivir lo que, en otra oportunidad, he llamado a una etapa de oro de la Facultad de Medicina de San Fernando, ${ }^{13}$ lamentablemente no de larga duración.* Con estos antecedentes se comprende mejor por qué, enfrentado el Decano Hurtado con una situación contraria al impulso de autenticidad académica que él venía forjando, lograra tanta comunión en sus pares y en los jóvenes profesores $\mathrm{y}$ hasta en un significativo número de alumnos. Pero todavía hay otro aspecto en la constelación de factores que entraron en la crisis que tampoco podemos soslayar.

\section{EL INICIO DEL DESBORDE POPULAR**}

La mitad de la centuria que está terminando, se caracterizó por dar paso a cambios profundos y acelerados en lo científico y tecnológico, así como en lo social que influyeron en todas las formas de la actividad humana y por ende en la Universidad.

Sin que al comienzo tomáramos conciencia plena del fenómeno las tareas de reconstrucción que siguieron a la segunda guerra mundial y el auge de innovaciones industriales derivadas de los avances científicos y tecnológicos, generados durante el conflicto bélico*** a la par de originar un ciclo de crecimiento

* Marcos Cueto, ${ }^{14}$ aceptando que en las décadas del cuarenta y cincuenta " el Perú tuvo un grupo selecto de investigadores de primera clase que bien podría ser considerado como típico de la élite científica de un país desarrollado", considera que la incorporación de nuevas tecnologías y la especialización diluyeron la visión global y que el discurso científico perdió en amplitud y dejó de ser interpretativo.

** José Matos Mar, ${ }^{15}$ ha descrito bajo el titulo "Desborde popular y crisis del Estado" la etapa crucial de este proceso que ocurre en la década del ochenta.

*** Si bien estos procesos se generan en los países de mayor desarro1lo, sus efectos se reflejan, en variable grado, también en los países pobres como Perú. económico, habían iniciado con la aparición del DDT, los quimioterápicos y los antibióticos, de un lado, y la cada vez mayor instantaneidad de las comunicaciones, por el otro, dos procesos de enorme gravitación social para el mundo en desarrollo: la explosión demográfica y la revolución de las expectativas crecientes de los pueblos. Incipientes entonces, estos procesos habrían de expresarse a plenitud más adelante. En 1940 la población del Perú era de 6'673,000 (64\% rural y 36\% urbana); en 1950 alcanzó 7'969,000 (60\% rural y 40\% urbana). La migración interna ya se estaba produciendo pero a un ritmo todavía no explosivo. Sin embargo, en la década siguiente el éxodo rural se duplica (51\% rural y $49 \%$ urbano). ${ }^{16}$ No puede llamar la atención, por lo tanto, que San Marcos tuviera 2,500 estudiantes en 1940 y cerca de 10,000 en 1950. La presión demográfica habría todavía que incrementarse en la década en la que ocurre la eclosión de San Fernando. De otro lado, no obstante la inestabilidad de nuestra vida republicana, el Perú logró, en las primeras décadas de este siglo, un crecimiento económico casi continuado. La agricultura en manos de los terratenientes costeños y la gran minería fundamentalmente, manejada por el capital extranjero, produjeron excedentes y así el esfuerzo empresarial privado dio pie a un esbozo de industrialización. Superamos con relativa facilidad la crisis de 1929 y en la media centuria, que es motivo de nuestro análisis, la economía peruana creció a una tasa que osciló entre el 4 y el 8\% anual. Lamentablemente este "desarrollo" no fue paralelo con un proceso redistributivo. Por el contrario, su ausencia se sumó a las revoluciones demográficas y de las expectativas, caldeando el fermento de la inquietud social. Estos ingredientes habían ya comenzado no sólo a masificar el alumnado sino que lo habían disminuido de nivel y conferido un creciente perfil andino. En la Facultad de Medicina, sin dejar de estar presentes estos fenómenos ocurrían con un menor acento. Obviamente, menudeaban las prédicas y reclamos de Justicia Social, Reforma Agraria y Cambios de Estructura que eran ávidamente asimilados por la juventud universitaria. Sin duda, la Universidad era una de las instituciones que había que modificar para 
hacer la revolución social. ¿Podría la puridad académica encauzar y enfrentar con éxito la dinámica de la creciente turbulencia social?

\section{EL CONFLICTO DE LA FACULTAD DE MEDICINA DE 1960}

El segundo gobierno del Dr. Manuel Prado fue posible por la decisión de última hora del partido aprista que, después de haber estado considerando apoyar al Dr. Hernando de Lavalle, volcó finalmente sus votos al pradismo. Numerosos amigos del Apra llegaron al Parlamento y fue clara la influencia de este partido en el régimen. La Ley 13417 del 8 de abril de 1960 restableció el cogobierno del tercio estudiantil. A lo largo de la gestación de este dispositivo la Facultad de Medicina, con el liderazgo de Alberto Hurtado, había repetidamente argumentado sobre los inconvenientes de una representación estudiantil muy numerosa y no calificada. Fue así posible introducir un artículo (el 34) que "por la índole de sus estudios" exoneraba a las facultades de medicina, la obligatoriedad del tercio estudiantil desde que establecía que "se regirán en lo administrativo y académico de acuerdo con sus reglamentos". Esta singular excepción no podía sino explicarse como resultado del respeto y prestigio, ya varias veces mencionado, que merecía el profesorado médico en la comunidad. Sin embargo, de inmediato se alzaron voces de protesta en profesores y estudiantes que consideraban que esta discriminación era incompatible con la unidad que requería la universidad peruana o que ella representaba una actitud retrógrada y antirreformista de los llamados "gorilas" (denominación utilizada por los extremistas para referirse a los catedráticos de Medicina). Luis Alberto Sánchez fue elegido Presidente de la Asamblea Universitaria encargada de formular el Estatuto de San Marcos y poco después, y por segunda vez, su Rector. Los conflictos tienen siempre un perfil antropomórfico. El destino quiso que en este caso dos ex-recoletanos fueran los principales protagonistas: Luis Alberto Sánchez y Alberto Hurtado.
Juzgado a la distancia podemos distinguir dos facetas en la crisis. Una externa, visible o formal y la otra menos reconocida en su momento, subyacente, dinámica y crecientemente vigorosa.

La primera fue simple. La mala experiencia del cogobierno del tercio en el período 1946-1948, había sensibilizado a los profesores. De otro lado, el impulso organizativo, el auge en la investigación, las innovaciones que había comenzado Hurtado en el profesorado (tiempos completos, dedicación exclusiva, residentado, etc.) y el aliento a los estudiantes promisorios, había creado una esperanza en que podría finalmente darse un paso para transformar la estructura científica del país. Obviamente para proseguir en este empeño se requería una Facultad que funcionase, una Facultad en donde no tuviera lugar la política y menos aun la politiquería. Para Hurtado, Delgado y una gran mayoría de profesores esto no sería posible con el tercio estudiantil. No cabía, por lo tanto, sino oponerse. Hurtado y sus profesores no negaban, sin embargo, la representación estudiantil en un número menor al tercio y con algún grado de calificación de los elegidos. Lo que se pretendía era evitar una intromisión irreflexiva, novel y sin experiencia en los complejos asuntos de la enseñanza y programación y más todavía la negativa ingerencia de la política y del partidismo en estos temas. La grita estudiantil fue en aumento y los parlamentarios sensibles al "clamor popular" no podrían resistir por mucho tiempo al asedio.

La otra faceta de la crisis tenía que ver con el momento social, político y económico que vivía el Perú. Un alumnado que había crecido desmesuradamente en los últimos lustros, cuyos niveles habían paralelamente descendido, una masa estudiantil que mayoritariamente y de buena fe creía en la bondad de las metas de justicia y reivindicación social que predicaban comunistas, apristas, socialistas, etc. ¿podría avizorar que en el fondo el planteamiento de los profesores de San Fernando era lógico y lo más conveniente para el progreso de la Universidad? Ciertamente que no. Tampoco lo podría comprender a cabalidad la casta política y menos 
aun las grandes mayorías nacionales. El Perú tendría que pasar por otras experiencias para que se llegara a comprender el sentido del gesto que asumieron los profesores de medicina.

Cuando el 25 de julio de 1961 el Congreso Nacional deroga el Art. 34 de la Ley Universitaria, la suerte está echada. El conflicto tan largamente vivido y sufrido estalla finalmente. De un lado teníamos una Facultad que desde su creación, se había caracterizado por contar con un cuerpo de profesores de gran ascendiente y prestigio en la comunidad, poco o nada contagiados por la política, que en las seculares pugnas universitarias siempre adoptaron la posición que mejor defendía los valores universitarios absolutos y que, no obstante las limitaciones del medio, habían logrado mantener un nivel de excelencia relevante. Había también una tradición estudiantil de vocación, genuino espíritu universitario, patriótico idealismo y afán de progreso, pero estaba inmersa en la vorágine del movimiento universitario muy agresivo y politizado en otras facultades. Sin embargo, hubo alumnos que aceptaron el reto y se solidarizaron con sus maestros. En el otro lado, bajo el manto de la ley y de la última expresión del proceso reivindicatorio que se suponía representaba la reforma universitaria, se escondía irrefrenable la fuerza social ya desatada que, con conciencia de su existencia o sin ella, reflejaban estudiantes, profesores y políticos que no entendían o condenaban la posición de esa mayoría de catedráticos sanfernandinos.

Horas después de la derogatoria del Art. 34 de la Ley Universitaria, aproximadamente 450 profesores presentaron su renuncia ante el Decano Dr. Honorio Delgado, que había sucedido hacía poco tiempo al Dr. Hurtado. ${ }^{17}$

Permanecieron en la Facultad alrededor de un centenar de profesores, la mayoría de mediana o de menor jerarquía.

Esa misma tarde los doctores Víctor Alzamora Castro, Hernán Torres Rodríguez, Jorge Voto Berna- les y Fernando Porturas Plaza, presentan una moción proponiendo la creación de la "Unión Médica Docente Cayetano Heredia"; antesala de la Universidad Peruana de Ciencias Médicas y Biológicas, hoy día Universidad Peruana Cayetano Heredia.

La renuncia no fue sólo un acto de identidad principista, solidaridad o consecuencia con las autoridades que habían dirigido la lucha. Para los profesores jóvenes, a tiempo completo y/o a dedicación exclusiva, fue además un gesto hermoso de renunciamiento y sacrificio por una causa considerada superior. Nadie podría estar seguro que el proyecto de una nueva Universidad resultaría viable. Otros sin depender necesariamente del salario universitario dejaban laboratorios y servicios, donde habían laborado fructíferamente por décadas. Variaba radicalmente una forma de trabajo que ellos habían contribuido a forjar. Para algunos el golpe fue dramático. Tal el caso de la Cátedra de Patología. Con mucho entusiasmo y esfuerzo, al amparo de las condiciones favorables antes indicadas, los jóvenes profesores, con la venia y apoyo del maestro Pedro Weiss y la asistencia económica de la Fundación Kellog habíamos finalmente culminado un anhelo largamente perseguido: la construcción y total equipamiento del nuevo Instituto de Patología. En la etapa de planificación del proyecto me tocó visitar los Laboratorios de Patología de no menos de cuatro de las más reputadas Universidades Norteamericanas y puedo asegurar que, en su momento, el Instituto de Patología de San Fernando no tenía nada que envidiar a esos Laboratorios. De hecho era entonces el mejor de Latinoamérica. Estábamos escogiendo con Don Pedro Weiss, Uriel García y Gerardo Boisset, entre los bocetos preparados por Quispez Asín, cuál sería el indicado para el hall principal del Instituto, cuando nos llegó la citación para la asamblea en la que se acordó la renuncia. Nunca llegamos a ocuparlo. Tanto esfuerzo e ilusión. Con mucha pena podíamos decir: en la puerta del horno se nos quemó el pan. Ver el más caro proyecto trunco y enfrentar la posibilidad de un temporal desempleo, cuando se está comenzando a constituir una familia, es vivencia que marca. Tomé la decisión de cautelar mejor el futuro de mis hijos y 
acepté dicotomizar mi esfuerzo profesional. Mantendría mi vocación por la enseñanza y la investigación, pero vería de realizar también algún ejercicio práctico de la especialidad. Ese fue mi personal desenlace de la crisis. Confieso con admiración que otros tuvieron más entereza y persistieron. No sé cuántos son, de los veinticinco profesores a dedicación exclusiva que tenía entonces San Fernando, pero quiero aprovechar de estas líneas para rendirles mi homenaje en las personas de dos grandes maestros: el Dr. Carlos Monge Cassinelli, que siguió y sigue invariable en el campo de la investigación y el Dr. Fernando Porturas Plaza, ejemplo de docente entregado a plenitud a sus alumnos.

\section{EPÍLOGO}

La renuncia masiva de los profesores de San Fernando trastocó la evolución de la medicina peruana. Los que permanecieron en la Facultad enfrentaron un desbarajuste y la tremenda tarea de rehacer los cuadros docentes. Los profesores de mejor nivel, mayor prestigio y producción científica se habían apartado. No era fácil reemplazarlos. Aun superando el factor hombre, pues un nombramiento puede sustituir a una renuncia, recuperar el trabajo en equipo y, sobre todo, el espíritu y la mística académica alcanzada requería, yendo bien las cosas, varios lustros. Más grande todavía era el desafío en el otro lado: hacer de la nada una nueva Universidad. Por más que se contara con incuestionable calidad humana y apoyo de sectores importantes de la sociedad, era una empresa que sino imposible exigiría mucha dedicación, sacrificio y tiempo. Así las cosas una conclusión es evidente. Se había interrumpido la continuidad en el progreso, en la facilidad para la asimilación de lo nuevo y en el mantenimiento de los niveles de excelencia logrados. San Fernando tenía la infraestructura y los equipos, la nueva Universidad los hombres. Si bien en sentido figurado se puede decir, como afirmara en medio de la crisis el Dr. Sánchez: "las instituciones nunca mueren", no es menos verdad que ellas sí enferman y languidecen. Y el resultado inmediato de esta crisis fue que la medicina peruana quedó lesionada.
Esta lesión se vio acrecentada en la medida en que los años en los que se desenvuelve el intento de recomposición de San Fernando y la creación y desarrollo de Cayetano Heredia, coinciden con el período de mayor avance en las nuevas tecnologías médicas. Se origina así un desfase. La exitosa aparición de la Universidad Peruana Cayetano Heredia no merece sino elogios. Señaló un camino y sentó pautas que sirvieron y sirven de modelos. No corresponde aquí incursionar en el análisis de su significación en el proceso educacional del país. Pero no se puede ignorar que la crisis internacional que se vive en los últimos tiempos, ha complicado y agravado el desfase aludido. No obstante los esfuerzos y buenas intenciones que pueden comprobarse en la Facultad de San Fernando en años recientes y de las bondades y excelencias de la Universidad Peruana Cayetano Heredia, debemos de reconocer que los niveles académicos, científicos y de ejercicio de nuestra medicina se han debilitado.

Mirando atrás y con perspectiva histórica cómo responder a las preguntas: ¿se justifica la renuncia? ¿cuál es el sentido profundo de la actitud de los docentes renunciantes?

Debo admitir que muchas veces, en los años que siguieron, me asaltaron esos interrogantes. Me rondaba siempre la proposición planteada por el Dr. Hugo Pesce, en la histórica asamblea final, "mejor es dar la lucha desde adentro". El tiempo es la mejor fuente de sabiduría. Lo que ha ocurrido en el Perú desde 1960 a la fecha, no ha hecho sino esclarecer y relievar el sentido de la firme y combativa postura sanfernandina.

El proceso político y social que hemos situado como una de las facetas en la crisis de 1960, continuó inexorable y alcanzó su punto culminante en 1968, cuando se dio inicio a lo que se ha denominado la "revolución peruana". Las decantadas metas reivindicacionistas tantos años predicadas por todos los sectores autocalificados de "izquierda", se ponían en ejecución. Se pensó que la justicia social, por todos reclamada, era factible en el corto plazo, que 
estaba a la vuelta de la esquina y que bastaba tan sólo modificar en profundidad las estructuras tradicionales del país para hacerla posible. El mecanismo de acumulación de excedentes económicos, que había reposado en el esfuerzo empresarial privado y logrado un traslado progresivo de los mismos del sector agrario a los incipientes desarrollos industriales, y en esta forma ha contribuido a un incremento casi continuado de nuestra economía, fue trastocado en sus raíces. El Estado asumió nuevas y crecientes responsabilidades en el proceso productivo. Los resultados son conocidos. Cesó el crecimiento en términos reales, no se logró una mejor redistribución de la riqueza y por el contrario las empresas asumidas por el Estado, comenzaron a constituir una pesada carga fiscal que agrava nuestros seculares problemas. Las experiencias en el mundo y en nuestra patria en los últimos años han facilitado una mejor visión de los desafíos que tenemos por delante. Si algo sorprende hoy día es la homogeneidad en el discurso político. Cuando escuchamos debatir sobre los temas acuciantes de la actualidad: economía,* salud, educación, alimentación, tratamiento del agro, incentivos para la exportación, ecología, política poblacional, violencia, terrorismo, etc. cuesta trabajo distinguir a los expositores en razón de su camiseta partidaria. Parecería que se ha perfilado un diagnóstico, aceptado por todos, y que las propuestas de soluciones, con diferencias mínimas y matices, caen dentro de un marco esencialmente común. Podría decirse que hemos aprendido qué es lo que no debemos hacer. La voz parece ser, hagamos las cosas bien. Ha cobrado momento sintetizar esta voluntad con un "cliché": modernidad. Debemos entrar a la modernidad se reclama con urgencia. Que en verdad no significa otra cosa que simple y llanamente, recogiendo las experiencias del pasado, hacer las cosas pensando en

* Durante las décadas del cincuenta y sesenta, el modelo cepalino de desarrollo se aceptó casi como dogma en América Latina. A mediados del ochenta crecieron las posiciones que la cuestionaban. Hoy es regla afirmar que no es el camino para el desarrollo de nuestros países. los intereses permanentes y prioritarios del país. No en función del interés político inmediato o de grupo o pensando en la proyección histórica reservada o en las elecciones del próximo año, sino en lo que en verdad habrá de beneficiar al Perú. Volviendo la mirada atrás y repreguntándonos ¿cuál fue, en última cuenta, el sentido de la actitud asumida por Hurtado y sus seguidores renunciantes? La respuesta fluye sola: simple y llanamente hacer las cosas bien teniendo sólo en cuenta el interés permanente y prioritario de la universidad y del país. Fue por lo tanto no sólo un gesto de rebeldía ante la sin razón, una reacción de sensatez, ${ }^{* *}$ sino un aislado y temprano grito reclamando hacer las cosas bien, una temprana expresión de que el Perú entrará con un paso firme a la modernidad.

Queda un último interrogante: ¿de no producirse la renuncia masiva de los profesores sanfernandinos, sería hoy distinto el panorama médico? Difícil respuesta. Me atrevo a pensar, cara a la magnitud de la faceta social y política que hemos definido como subyacente en la crisis, que la masificación estudiantil, el deterioro económico y el desfase tecnológico eran fenómenos que, entonces recién desatados, habrían de ser incontenibles. El surgimiento de la Universidad Peruana Cayetano Heredia creó, sin embargo, un modelo, una nueva isla de nacional excelencia que da pie y esperanza, para seguir bregando para acortar y eventualmente cerrar la brecha que nos separa de los centros universitarios desarrollados. La imperiosa necesidad de evitar el progresivo deterioro de la universidad peruana, es hoy uno de los temas sobre el tapete. Con acierto, recientemente, el doctor Ricardo Abugattas ${ }^{19}$ basado en su personal experiencia como alumno y profesor de la Facultad de Medicina sugiere, animado por la corriente de renovación que hoy se alienta, que ha llegado el

\footnotetext{
** Es interesante comprobar que años después el Dr. Luis Alberto Sánchez autocalificándose "uno de los pioneros de la participación estudiantil en los Consejos Universitarios" afirmara que "la captura de las delegaciones estudiantiles con fines partidarios... deshizo aquella ilusión”, pág. 203. ${ }^{18}$
} 
momento de revaluar y reformular la enseñanza de la medicina en el Perú. Meta ambiciosa que quizá no veremos alcanzada los de la generación.de la media centuria, pero camino obligatorio para que, haciendo honor a la tradición heredada de San Fernando, Alma Mater de la medicina peruana, entremos con esperanza, fe y optimismo en el nuevo siglo.

\section{REFERENCIAS BIBLIOGRÁFICAS}

1. Lastres, J. B. Historia de la Medicina Peruana. La medicina en el Virreynato, UNMSM. Publicación del Cuarto Centenario, Imprenta Santa María, Lima 1951.

2. Arias-Schreiber, J. La Escuela Médica Peruana, 18111972, Editorial Universitaria, Lima, 1972.

3. Lip, C., Lazo, O. y Brito, P. El trabajo médico en el Perú. Organización Panamericana de la Salud, UPCH, Facultad de Medicina Alberto Hurtado, Lima, 1990.

4. Basadre, J. Historia de la República, Tomo IX, Talleres Gráficos P. L. Villanueva S.A., Lima, pp. 4330-4347, 1964.

5. Sánchez, L. A. Testimonio Personal. El Aquelarre 19001931, Mosca Azul Editores, Lima, 1987.

6. Sánchez, L. A. Testimonio Personal, Tomo 3. La Caldera del Diablo, 1945-1956, Mosca Azul Editores, Lima.

7. FACULTAD DE MEDICINA, UNMSM. Exposición al País, Lima, julio de 1960.

8. Tello, J. C. Reforma Universitaria. Ensayos y Discursos, Lima, 1928.

9. Arias-Stella, J. "Significado de la obra del Profesor Alberto Hurtado", Tribuna Médica, 1973 N 406, A2, Lima.

10. Guerra-García, R. "La investigación científica en la Universidad Peruana", Cuadernos del CONUP, 1976 $\mathrm{N}^{\circ}$ 20-21, Lima.
11. Sobrevilla, D. Las ideas en el Perú contemporáneo. Historia del Perú, Tomo XI, Editorial Juan Mejía Baca, Lima, 1980.

12. Pérez Tamayo, R. Existe el método científico? Historia y Realidad, Fondo de Cultura Económica, México, 1990.

13. Arias-Stella, J. Discurso con ocasión de la incorporación del Dr. Róger Guerra-García, como Miembro Titular de la Academia Nacional de Medicina. Sesión del 29 de abril 1988, Lima.

14. Cueto, M. Excelencia científica en la Periferia, Consejo Nacional de Ciencia y Tecnología (CONCYTEC), Lima, 1989.

15. Matos Mar, J. Desborde popular y crisis del Estado. Perú Problema, 21, Instituto de Estudios Peruanos, Lima, 1984.

16. Wicht, J. J. Problemas poblacionales peruanos. La situación demográfica del Perú, AMIDEP, 1980, 17-93, Lima.

17. Torres Zamudio, C. "Evocando la creación de la Universidad Peruana Cayetano Heredia", Actualidad Médica, 1990, Año 2, Nº 5, pp. 27-28, Lima.

18. Sánchez, L. A. Testimonio Personal, Tomo 4. Las confidencias de Caronte, 109-124, Mosca Azul Editores, Lima, 1987.

19. Abugattas, R. La profesión médica en el Perú y su enseñanza, Acta Médica Peruana, 1991, Vol. XV, N 2, 68-69, Lima. 